\title{
Stevia rebaudiana germplasm characterization using microsatellite markers and steviol glycosides quantification by HPLC
}

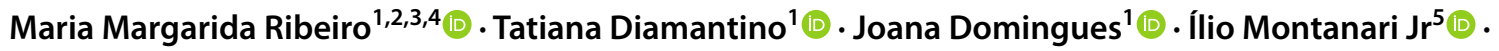 \\ Marcos Nopper Alves ${ }^{5}$ (D) . José Carlos Gonçalves ${ }^{1,2,3}$ (1)
}

Received: 4 January 2021 / Accepted: 19 March 2021 / Published online: 3 April 2021

(c) The Author(s) 2021

\begin{abstract}
Stevia rebaudiana Bertoni, Asteraceae, is an herbaceous perennial plant native to Paraguay. This species is considered since ancient times a medicinal plant with important bioactive compounds and pharmacologic and food properties, namely diterpenes glycosides. The high natural sweetener potential stevioside and rebaudioside A produced by $S$. rebaudiana plants are suitable sucrose substitutes, and their obtention is influenced by environmental, phytosociological, and genetic factors. The plants' genetic profile and sweet potential depiction are needed for suitable plant selection for improvement and deployment. Thirty-one S. rebaudiana accessions grown in the same plot where leaves samples were collected in early 2019, were genotyped using six microsatellite markers, including two steviol glycosides biosynthesis functionally involved markers. Additionally, an aqueous extract of each sample was obtained in a water bath and purified by SPE for stevioside and rebaudioside A quantification by normal phase HPLC. Stevioside and rebaudioside A contents varied between $0.53-7.36 \%\left(\mathrm{w} \mathrm{w}^{-1}\right)$ and $0.37-3.60 \%\left(\mathrm{w} \mathrm{w}^{-1}\right)$, respectively. Two genotypes displayed interesting ratios of rebaudioside A/stevioside (number 3 and 33). The level of genetic similarity between genotypes was tested through a pairwise similarity coefficient, and two groups of individuals had the same fingerprinting. Strong relatedness was found within genotypes, possibly due to cloning, thus, influx of new germplasm ought to be made to prevent mating between relatives, and for further selection and genetic improvement.
\end{abstract}

Keywords Fingerprint $\cdot$ Genetic improvement $\cdot$ Germplasm $\cdot$ Stevioside $\cdot$ Molecular markers $\cdot$ Rebaudioside A

\section{Introduction}

The genus Stevia consists of approximately 230 species [1, 2], and Stevia rebaudiana features the sweetest essence [3]. Stevia genus is distributed worldwide, ranging from the southern parts of the USA to Argentina and Brazil. Nowadays, Stevia cultivation has spread worldwide, including
Europe, propagated through seed and cuttings [2]. S. rebaudiana Bertoni $(2 \mathrm{n}=22)$ is a perennial and branched shrub of the Asteraceae family, native to north-eastern Paraguay $[4,5]$. Since ancient times, this plant has been known as a sweetener due to the high content of diterpene glycosides [6], found in the leaves (present in a minor amount in shoots, roots, and flowers) in concentrations from 4 to $20 \%$ of dry

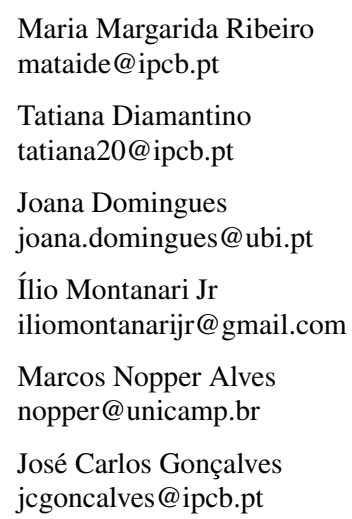

1 Centro de Biotecnologia de Plantas da Beira Interior, Escola Superior Agrária de Castelo Branco, 6001-909 Castelo Branco, Portugal

2 Instituto Politécnico de Castelo BrancoEscola Superior Agrária, 6001-909 Castelo Branco, Portugal

3 Centro de Recursos NaturaisAmbiente e Sociedade (CERNAS) - Instituto Politécnico de Castelo Branco, 6000-084 Castelo Branco, Portugal

4 Forest Research Centre, School of Agriculture, University of Lisbon, Tapada da Ajuda, 1349-017 Lisbon, Portugal

5 CPQBA/UNICAMP - Centro Pluridisciplinar de Pesquisas Químicas Biológicas e Agrícolas, Universidade Estadual de Campinas, São Paulo, Brazil 
matter $[5,6]$. Stevioside and rebaudioside A are the interesting steviol glycosides sugar-substitutes substances, which tend to accumulate in the aging tissues, thus, older leaves contain more sweeteners than younger ones. Conversely, at the beginning of flowering, the concentrations of glycosides in the leaves begin to decrease [1]. In general, stevioside is found in higher amounts than rebaudioside A, thus both substances' production is negatively correlated. Rebaudioside $\mathrm{A}$ is a better commercial product than stevioside, due to higher solubility in water and sweeter capacity, and the latter is responsible for aftertaste bitterness [1, 7]. According to Ceunen and Geuns [8], this ratio can be influenced by ontogeny and day length, with larger ratios obtained during the vegetative stage under short days. Rebaudioside A/stevioside ratio in leaves, together with the steviol-glycosides concentration and the leaf dry yield are significant economic parameters for stevia genotypes evaluation [9]. Moreover, in the former study, the ratio of rebaudioside A to stevioside revealed a significant effect of the genotype, in a trial conducted with two genotypes. An interesting approach to overcome the bitter aftertaste and improve the Stevia sweetness potential is the biotransformation of stevioside into rebaudioside A. Adari et al. [10] explained the stevioside enzymatic transglycosylation performed via the Stevia leaves pre-treatment with cellulose. The steviol-glycosides are currently used as sweet-tasting non-caloric food additives, due to obesity and diabetes rates rise worldwide $[4,7,11]$. Furthermore, displays therapeutic properties, such as antimicrobial, anti-inflammatory, antioxidant, antiviral, anti-jaundice, cardiotonic, and diuretic [7, 12]. The leaves and extracts can be taken raw or cooked, and added to various food products as sweeteners, due to the steviol-glycosides thermostability [13]. Steviol-glycosides were approved for use as a food additive in Europe represented by the code E960, in 2011 [14]. The existence of genetic variability in plant genetic resources provides plant breeders with the possibility to develop new and improved cultivars with desirable characteristics to include stakeholders-preferred traits (e.g., [15]).

Some genetic studies were reported in this species using markers with several limitations, such as RAPDs [16-18], AFLPs, and ISSRs [19-21], due to their dominance and to RAPDs reproducibility problems [22]. Dominance leads to recessive allele frequency underestimation biasing genetic diversity estimates [23, 24]. Thus, for fingerprinting purposes, microsatellite markers (SSRs) are the markers of choice, owing to their high polymorphism, multiallelism, codominance, high reproducibility, and uniform distribution in the genome [25-27]. These markers can competently be used in the genotyping process with a good genome sampling, which makes them suitable to estimate genotypes relatedness that requires multilocus genotype identification [28]. Kaur et al. [29] and Bhandawat et al. [30] were the pioneers in microsatellite markers development and use in
S. rebaudiana and, recently, from freely available expressed sequence data (ESTs), and Cosson et al. [31] also developed molecular markers (EST-SSRs) for population genetic and germplasm characterization studies. Recently, also a group of $S$. rebaudiana genotypes from Paraguay were studied with SSR and ISSR [32], and analysed as dominant markers. Additionally, molecular data can be pooled with biochemical data to detect stevia genotypes suitable to start a breeding program [18].

The use of microsatellite loci and the development of statistical tools made it possible inferring kin relationships from molecular data, in particular 'relatedness', meaning the estimation and assignment of pairs or groups of individuals to categories of relationship or a measure of the fraction of alleles shared identical by descent among individuals [33]. Indeed, to ensure that levels of co-ancestry and inbreeding among selected plants are kept to a minimum, it is advantageous to know their relatedness [34]. Additionally, besides avoiding related individuals (in particular for outcrossed species), it is important to accurately identify the genotypes and to distinguish the new cultivars for registration purposes. The germplasm fingerprint and cultivar identification with molecular markers-based grew in importance, due to generated data quality and speed, and also because morphological characteristics are influenced by environmental factors [22, 35-37].

In addition to the genetic and environmental factors that can influence the steviol-glycosides content, the analytical methodology selection is important to obtain an efficient protocol for plant bioactive compounds present extraction, purification, and quantification. The Stevia leaves steviolglycosides were generally obtained subsequently to hot water application, followed sometimes by solid-phase extraction. However, extraction methods using other solvents, such as ethanol and methanol or even supercritical fluid extraction, were also described [38]. These solvents, namely methanol, appear to be used in the extraction process, presumably to improve extraction efficiency and facilitate the individual steviol-glycosides separation. However, regarding industry food safety, the use of water for extraction should be favoured over methanol or ethanol use [11]. Additionally, the water extraction seems the extraction method to be used in this case, given that rebaudioside A water solubility is higher compared to stevioside [11]. Several HPLC methodologies used to quantify the steviol-glycosides in $S$. rebaudiana leaves samples were reported in the literature [38 and references therein, 39]. Matrix load dramatically shortens chromatographic columns' lifetime, thus the analytical purification method, including solid phase extraction (SPE), must be applied [7, 38]. Finally, the HPLC methods was considered as the most reliable and simple method for the quantification of glycosides [40]. 
The genotypes collection of $S$. rebaudiana established in the Pluridisciplinary Center for Chemical, Biological and Agricultural Research, State University of Campinas, São Paulo, Brazil (CPQBA/UNICAMP) were studied for breeding purposes. The aims of the present study were: (i) to genotype 31 individuals with microsatellite markers to compute the genetic diversity, the fingerprint, and the relatedness, and (ii) to identify the genotypes that produce the highest rebaudioside $\mathrm{A} /$ stevioside ratio.

\section{Material and methods}

\section{Plant material}

We have studied 31 individuals from the $S$. rebaudiana germplasm plot established in the campus of the CPQBA/ UNICAMP (Pluridisciplinary Center for Chemical, Biological and Agricultural Research. State University of Campinas, São Paulo, Brazil). The S. rebaudiana seeds were previously collected in the species' region of origin, but the exact location is unfortunately unknown. Four to five leaves sampled in each genotype from different parts of the plant were collected from January to February 2019. The genotypes were grown in the same plot with $1 \times 0.5 \mathrm{~m}$ spacing, and 5 to 10 replications per genotype and the sampling was made just before flowering. Afterward, the leaves were lyophilized and frozen at $-80^{\circ} \mathrm{C}$.

\section{DNA extraction and amplification}

DNA was extracted from $100 \mathrm{mg}$ of fresh leaves of each $S$. rebaudiana genotype, using the $\mathrm{CTAB}$ method as described by Doyle and Doyle [41], and a high concentration of pure genomic DNA was obtained. The genomic DNA from all individuals was amplified using six microsatellites (SSR) markers selected from literature (Table 1). The two selected SUGMS (Stevia UniGene derived MicroSatellites) primers (Table 1) are putatively related to the steviol biosynthesis [30]. All amplifications were conducted separately for each primer pair and forward primers were 6-FAM fluorescently labelled. PCR reactions with the SUGMS primers (Table 1) were performed in $10 \mu \mathrm{L}$ a total reaction volume, containing 50-60 ng of template DNA, 0.2 U Supreme NZYTaq $2 \times$ Colourless Master Mix ${ }^{\circledR}$ separate $\mathrm{MgCl}_{2}$ (Nzytech, Lisbon, Portugal), $2.5 \mathrm{mM} \mathrm{MgCl}_{2}$, and $1.0 \mu \mathrm{M}$ of each primer. The amplifications were performed on a UNO96 Gradient thermocycler (VWR $®$, Leuven, Belgium). The PCR protocol consisted of an initial denaturation step of 4 min at $94{ }^{\circ} \mathrm{C}$, followed by 35 amplification cycles composed of denaturation $\left(1 \mathrm{~min}\right.$ at $94{ }^{\circ} \mathrm{C}$ ), annealing ( $1 \mathrm{~min}$ at optimal annealing temperature for each pair, see Table 1) and polymerizing $\left(1 \mathrm{~min}\right.$ at $\left.72{ }^{\circ} \mathrm{C}\right)$. After the amplification cycles, a final extension step was performed for $7 \mathrm{~min}$ at $72{ }^{\circ} \mathrm{C}$.

The PCR reactions with the 'gi' primers (Table 1) were performed in a $10 \mu \mathrm{L}$ total reaction volume, containing 50-60 ng of template DNA, 0.8 U Supreme NZYTaq $2 \times$ Colourless Master Mix ${ }^{\circledR}$ separate $\mathrm{MgCl}_{2}$ (Nzytech, Lisbon, Portugal), $2.5 \mathrm{mM} \mathrm{MgCl}_{2}$, and $1.5 \mu \mathrm{M}$ of each primer. The amplifications were performed in the same thermocycler, programmed with an initial denaturation step of $5 \mathrm{~min}$ at $95{ }^{\circ} \mathrm{C}$, followed by 40 amplification cycles composed of denaturation $\left(1 \mathrm{~min}\right.$ at $\left.95^{\circ} \mathrm{C}\right)$, annealing ( $1 \mathrm{~min}$ at optimal annealing temperature for each pair, see Table 1) and polymerizing $\left(2 \mathrm{~min}\right.$ at $72{ }^{\circ} \mathrm{C}$ ). The PCR reaction with the stvia036 primer was performed in a $10 \mu \mathrm{L}$ total reaction volume, containing 50-60 ng of template DNA, 0.5 U Supreme NZYTaq $2 \times$ Colourless Master Mix ${ }^{\circledR}$ separate $\mathrm{MgCl}_{2}(\mathrm{Nzy}-$ tech, Lisbon, Portugal), $2.5 \mathrm{mM} \mathrm{MgCl}_{2}$, and $2.0 \mu \mathrm{M}$ of each primer (Table 1). The amplifications were performed in the same thermocycler, programmed with an initial denaturation step of $15 \mathrm{~min}$ at $95^{\circ} \mathrm{C}$, followed by 35 amplification cycles
Table 1 Primers used for the SSRs analysis

\begin{tabular}{lllll}
\hline Primer & Sequence 5'-3' & Size range (bp) & $\begin{array}{l}\text { Annealing } \\
\text { temp. }\left({ }^{\circ} \mathrm{C}\right)\end{array}$ & References \\
\hline SUGMS28 & $\begin{array}{l}\text { F: CAAATTGGGAATTGCAGCTT } \\
\text { R: GACAAACAAGCCGAGAGAGG }\end{array}$ & $210-310$ & 55 & Bhandawat et al. [30] \\
SUGMS43 & $\begin{array}{l}\text { F: CCAATCTACAATTGCCACAAGA } \\
\text { R: TTTTCCGAGGTTTTGGTTG }\end{array}$ & $225-255$ & 55 & Idem \\
gi18465444 & F: ATGAAAGCGAGCCTGATGAT & $100-610$ & 56 & Kaur et al. [29] \\
& R: TCAAGCAACGATTCTTTCCA & & & \\
gi16949765 & $\begin{array}{l}\text { F: CAAGGCTTGCTCCGAAATAC } \\
\text { R: TCATCTGCAAGTGCTTCCTC }\end{array}$ & $680-900$ & 56 & Idem \\
gi18465673 & $\begin{array}{l}\text { F: CGGGTTAGAAGGAAACGTGA } \\
\text { R: AAGTTTCCACCAACCCATCA }\end{array}$ & $500-800$ & 56 & Idem \\
stvia036 & $\begin{array}{l}\text { F: TGTCTCTGACAAAATTTATACGG } \\
\text { R: TTGTCTGTCACCCTGTGG }\end{array}$ & & & \\
\end{tabular}


composed of denaturation $\left(30 \mathrm{~s}\right.$ at $94{ }^{\circ} \mathrm{C}$ ), annealing ( $45 \mathrm{~s}$ at $55{ }^{\circ} \mathrm{C}$, see Table 1$)$ and polymerizing $\left(1 \mathrm{~min}\right.$ at $\left.72{ }^{\circ} \mathrm{C}\right)$. After the amplification cycles, a final extension step was performed for $5 \mathrm{~min}$ at $72{ }^{\circ} \mathrm{C}$. All PCR products were diluted in $50 \mu \mathrm{L}$ of Milli-Q water and an aliquot of $3.0 \mu \mathrm{L}$ of each dilution was mixed with $10 \mu \mathrm{L}$ of formamide and $0.2 \mu \mathrm{L}$ of LIZ-600 size standard. Genotyping was performed with an ABI 3130 Genetic Analyzer (Applied Biosystems, Foster City, CA, USA), the fragment analysis was performed using GeneMapper 4.0 software (Applied Biosystems, Foster City, CA, USA), and the data manually scored.

\section{Aqueous extracts of S. rebaudiana}

Lyophilized leaf samples were grounded with a mortar and pestle. Sample extracts were prepared by weighting $0.4 \mathrm{~g}$ of dried leaf powder and adding $8 \mathrm{~mL}$ of distilled water into $15 \mathrm{~mL}$ centrifuge tubes, afterward mixed in the vortex and placed in a $90{ }^{\circ} \mathrm{C}$ water bath for $30 \mathrm{~min}$. Subsequently, the extracts were cooled at ambient temperature and centrifuged at $4400 \mathrm{rpm}$ for $30 \mathrm{~min}$ at $4{ }^{\circ} \mathrm{C}$ (CLINIconic 75003623, Thermo Scientific, Massachusetts, EUA). From each centrifuged extract, the supernatant was transferred to a $25 \mathrm{~mL}$ volumetric flask. The pellet was reused for two more extractions and the supernatants transferred to the same volumetric flask. Finally, the volumetric flask was filled to $25 \mathrm{~mL}$ with distilled water.

\section{Stevioside and rebaudioside $A$ extracts purification and HPLC quantification}

Both steviol-glycosides were quantified according to the improved HPLC method described by Woelwer-Rieck et al. [38], with some modifications. The extracts were purified two times by solid-phase extraction (SPE) with the C18-E column (100 mg, $1 \mathrm{~mL}, 55 \mu \mathrm{m}, 70 \AA$ A, Strada, Phenomenex, California, USA), with a constant vacuum pressure of 15 inHg. Columns were first conditioned with $3 \mathrm{~mL}$ of methanol and $3 \mathrm{~mL}$ of Milli-Q water and subsequently charged with $400 \mu \mathrm{L}$ of extract, followed by washing with $3 \mathrm{~mL}$ of Milli-Q water and $5 \mathrm{~mL}$ of acetonitrile: Milli-Q water (20:80 $\mathrm{v} / \mathrm{v})$. Columns were left to dry for $3 \mathrm{~min}$ and then, steviolglycosides were eluted with $2 \mathrm{~mL}$ of acetonitrile:Milli-Q water $(75: 25 \mathrm{v} / \mathrm{v})$ and recovered in a $5 \mathrm{~mL}$ volumetric flask.

Seven stevioside (Cayman Chemical, Michigan, USA) and rebaudioside A (Extrasynthese, Genay, France) standard solutions were prepared in acetonitrile:Milli-Q water $(75: 25 \mathrm{v} / \mathrm{v})$ in the concentration range of $5-800 \mu \mathrm{g} \mathrm{mL} \mathrm{m}^{-1}$. Both standard solutions and purified extracts were filtered with a $0.45 \mu \mathrm{m}$ nylon filter $(0.4 \mathrm{~mm}$ diameter, Technocroma, Barcelona, Spain) before loading in HPLC.
The linearity was assessed by injecting standard solutions of stevioside and rebaudioside A from 10 to $800 \mu \mathrm{g} \mathrm{mL}^{-1}$, using six different concentrations, and all standard solutions were injected in two different days. Standards were loaded in triplicate and each purified extract in duplicate into HPLC (Agilent 1100 series, with a quaternary pump, autosampler, diode array detector, degasser, thermostat, and data system), equipped with an $\mathrm{NH}_{2}$ column (Purospher® STAR $\mathrm{NH}_{2}$, $250 \times 4 \mathrm{~mm}, 5 \mu \mathrm{m})$ under the following conditions: $20 \mu \mathrm{L}$ of injection volume, $210 \mathrm{~nm}$ wave-length, mobile phase: HPLC grade acetonitrile:Milli-Q water $(75: 25 \mathrm{v} / \mathrm{v}), 1 \mathrm{~mL} \mathrm{~min}^{-1}$ constant flow rate, $20 \mathrm{~min}$ at $36^{\circ} \mathrm{C}$. The qualitative determination was achieved by comparing the stevioside and rebaudioside $\mathrm{A}$ standard solutions retention times with those of the samples. The quantification was possible by applying the computed calibration curves equations. The linear regression curves of stevioside and rebaudioside $\mathrm{A}$ are presented below were obtained (both adjusted the interception in 0 ):

Stevioside: $\mathrm{Y}=4.7091 \mathrm{X}\left(\mathrm{r}^{2}=0.9994\right)$

Rebaudioside A: $\mathrm{Y}=4.1668 \mathrm{X}\left(\mathrm{r}^{2}=0.9998\right)$

where $\mathrm{Y}$ is the peak area $\left(\mathrm{mAU} \mathrm{s}^{-1}\right)$ and $\mathrm{X}$ is concentration $\left(\mu \mathrm{g} \mathrm{mL}^{-1}\right)$ (unpublished results). The stevioside and the rebaudioside A concentration were represented in $\% \mathrm{w} \mathrm{w}^{-1}$ (steviol glycoside/dry leave).

\section{Genetic data analysis}

The genetic diversity parameters $\mathrm{Na}$ (number of alleles), $\mathrm{Ne}$ (effective number of alleles), Ho (observed heterozygosity), $\mathrm{He}$ (unbiased expected heterozygosity), and F (fixation index) were obtained with the GenAIEx software version 6.502 [42]. To test the genotypes pairwise relatedness the Lynch and Ritland [43] kinship coefficient was used (hereafter LR), and this coefficient was selected for it was considered the most accurate in a simulation with a set of relatedness coefficients validated with an elite group genetic similarity of Eucalyptus globulus with known pedigree [44]. The dendrogram (UPGMA method) was performed using the kinship matrix and the software NTSyS-PC version 2.11 [45]. The genetic relationship among genotypes was further analyzed by principal coordinate analysis (PCoA) using GenAIEx, based on the same pairwise relatedness matrix. The maximum deviation method was used for the factorial rotation and the main components were extracted, with the first main component and the second main component being the leading coordinates. The LR pairwise matrix, the genotypes multilocus comparison analysis, were computed in the GenAlEx. 


\section{Results}

\section{SSRs analysis}

The analysis of the genetic diversity parameters (Table 2) revealed that the number of alleles per locus $(\mathrm{Na})$ ranged from 3 to 6 , averaging 4 per locus. The effective number of alleles per locus $(\mathrm{Ne})$ was 3.02, lower than the average $\mathrm{Na}$, but reflecting more accurately genetic diversity. Indeed, three loci displayed the same $\mathrm{Na}$ (3) and two had higher $\mathrm{Ne}$ than the other one (gi16949765), also reflected in higher genetic diversity values: the SUGMS43 and Stevia36 loci (Table 2).

However, the loci with higher $\mathrm{Na}$, in general, had higher $\mathrm{Ne}$ and Ho values (gi18465444 and gi18465673), which

Table 2 Genetic diversity parameters by locus for the 31 genotyped $S$. rebaudiana individuals

\begin{tabular}{llllll}
\hline Locus & $\mathrm{Na}$ & $\mathrm{Ne}$ & $\mathrm{Ho}$ & $\mathrm{He}$ & $\mathrm{F}$ \\
\hline gi18465444 & $\mathbf{5}$ & $\mathbf{4 . 0 6}$ & $\mathbf{0 . 8 4}$ & $\mathbf{0 . 7 7}$ & -0.11 \\
gi16949765 & 3 & 1.60 & 0.45 & 0.38 & -0.21 \\
gi18465673 & $\mathbf{6}$ & $\mathbf{3 . 5 9}$ & $\mathbf{0 . 8 7}$ & $\mathbf{0 . 7 3}$ & -0.21 \\
SUGMS28 & 4 & 3.42 & 0.77 & 0.72 & -0.09 \\
SUGMS43 & 3 & 2.66 & 0.84 & 0.63 & -0.34 \\
Stvia36 & 3 & 2.81 & 0.81 & 0.65 & -0.25 \\
Mean & 4 & 3.02 & 0.76 & 0.65 & -0.20 \\
SE & & 0.35 & 0.06 & 0.06 & 0.04 \\
\hline
\end{tabular}

Values in bold correspond to primers with the highest genetic diversity parameters: $\mathrm{Na}, \mathrm{Ne}, \mathrm{Ho}$ and $\mathrm{He}$

$\mathrm{Na}$ number of alleles, $\mathrm{Ne}$ effective number of alleles, $\mathrm{Ho}$ observed heterozygosity, $\mathrm{He}$ expected unbiased heterozygosity, $\mathrm{F}$ fixation index were found in putative non-coding regions, values in bold in Table 2. However, the SUGMS43 locus, found in the coding region, had appreciable genetic diversity $(\mathrm{Ho}=0.84)$, though with only three alleles, yet with even frequencies (data not shown).

The total observed heterozygosity (Ho) ranged from 0.45 to 0.87 , with an average of 0.76 . There was an excess of heterozygous in all loci since the observed is higher than that expected heterozygosity (Ho $>\mathrm{He}$ ), while a lower difference is found in the SUGMS28 locus (Table 2). However, the analyzed germplasm is a group of individuals unlikely in Hardy-Weinberg equilibrium.

\section{Genetic distances and clustering}

Genotypes were grouped according to the level of genetic similarity using the LR index. In the PCoA analysis, based on the kinship distance (LR), individuals with the same genotype plotted together (black circles, Fig. 1), but the remaining ones were, in general, well individualized, except in the case of genotypes 2, 5 and 17 . Both the first and the second component explained $\approx 6 \%$ of the total variation and the total variation explained was $12 \%$.

The dendrogram (UPGMA method) obtained with the kinship matrix (LR) (Fig. 2) reveals the relatedness among $S$. rebaudiana genotypes. This analysis separated the genotypes into two groups, with a very low degree of similarity (group 1: 4, 7, 9, 15, 17, 18, 19, 21, 23, 25, 26, 27, 30, 33, and 31; group 2: 1, 2, 3, 4, 5, 6, 8, 10, 11, 12, 13, 14, 20, 22, 24, 28 and 29). According to the literature for a value of LR coefficient $>0.25$ the genotypes may be considered half-sibs, resulting from cross-fertilization; for LR $>0.5$ the genotypes may be full-sibs, sharing both mother and father,
Fig. 1 The principal component analysis was based on the LR pairwise kinship matrix. Black circles embodied individuals with the same genotype, all the others were represented by white diamonds. Both the first and the second components account for $6 \%$ of the total variation.

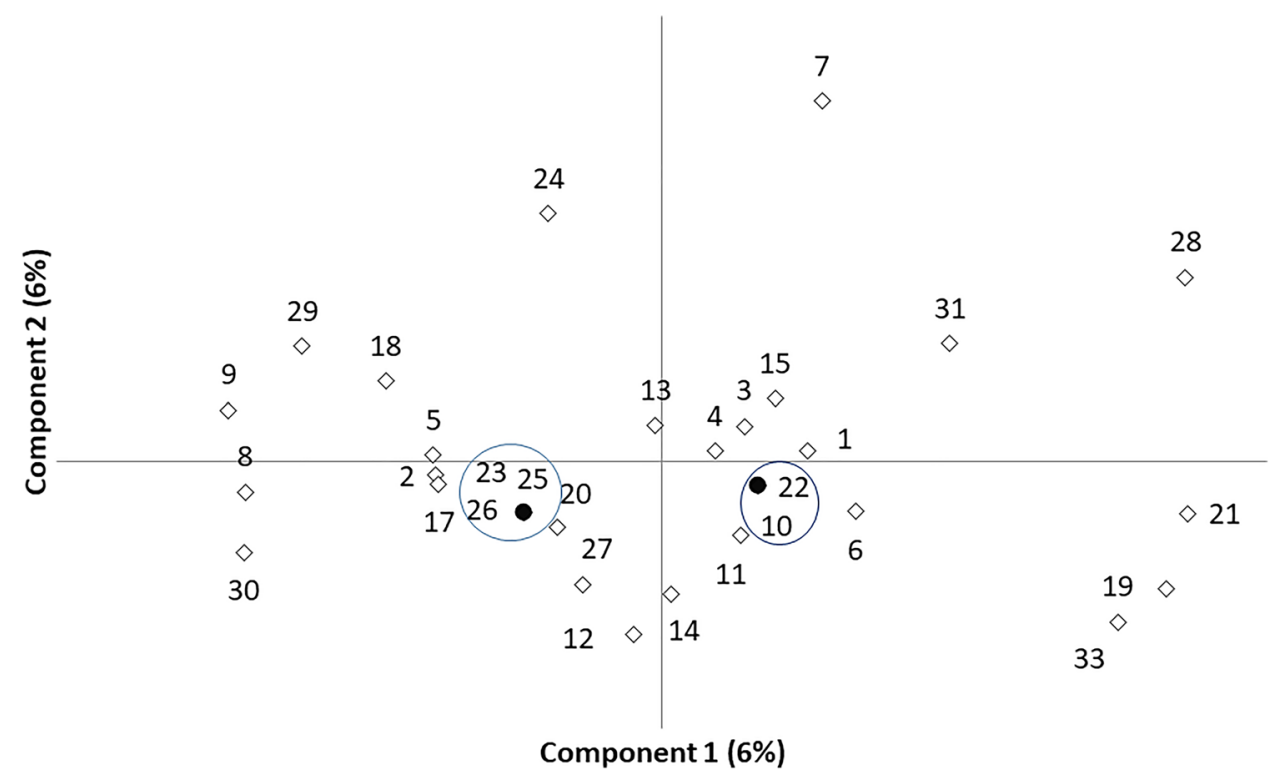




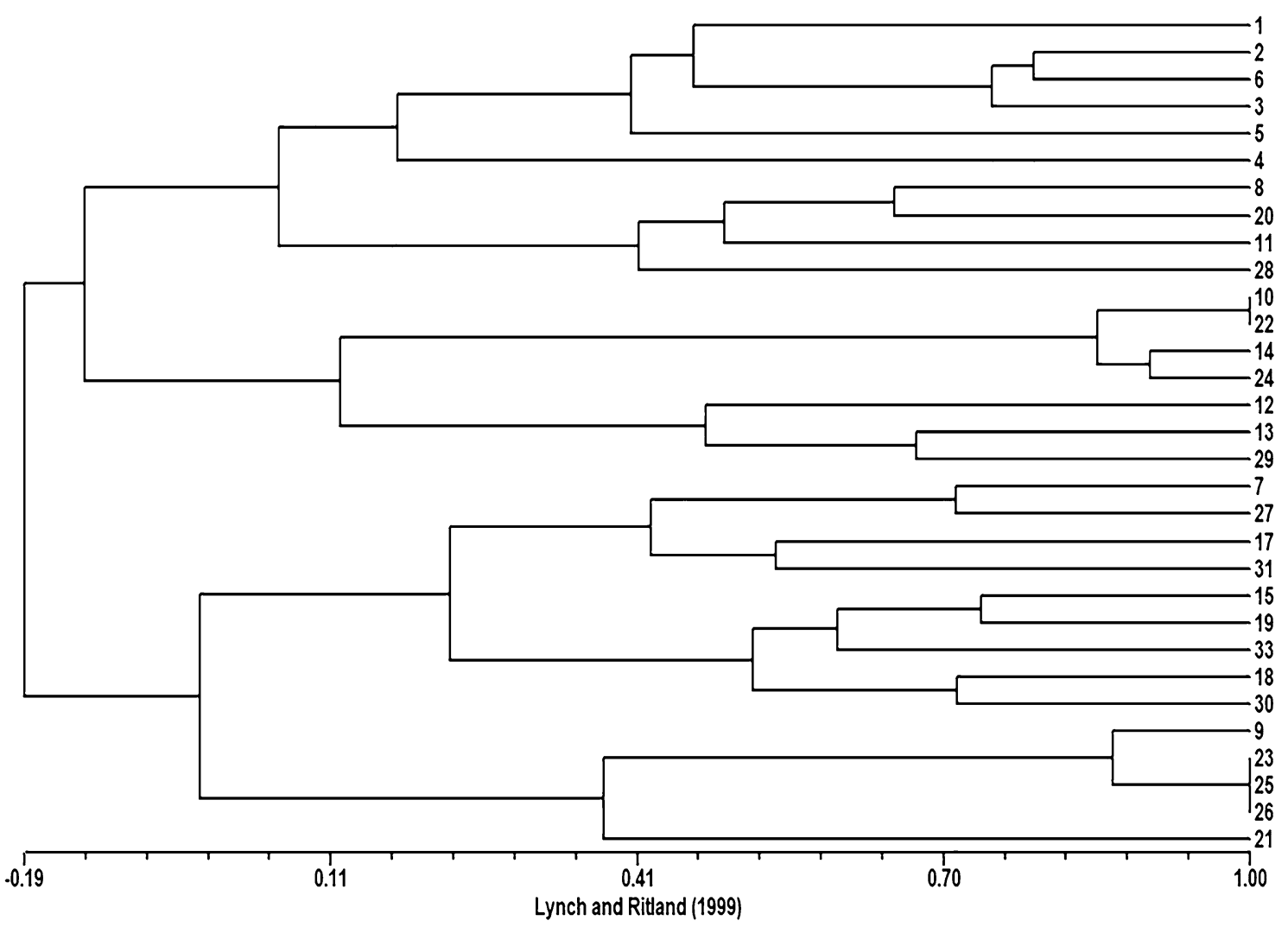

Fig. 2 Accessions' dendrogram using the UPGMA clustering methods and the Lynch and Ritland [43] pairwise kinship matrix

for LR $>0.67$ they may be the result of self-pollination, and for $L R=1$ for the same genotype or clones [33, 44]. Indeed, two sets of individuals shared the same multilocus genotype (1st set: 10 and 22, and 2nd set: 23, 25, and 26), meaning that they share the same genotype, possibly a sampling/labeling error or clones. The fingerprinting of the two sets that displayed the same genotype are listed in Table S1.

\section{HPLC quantification of steviol-glycosides}

The contents of stevioside and rebaudioside A in the different genotypes were determined using calibration curves obtained by authentic standards. The linearity corresponds to the method's ability to provide results directly proportional to the analyzed compound concentration, within a given interval. The calibration curves were linear in the range of $10-800 \mu \mathrm{g} \mathrm{mL}^{-1}$ for both steviol glycosides standards and the linearity of the HPLC method was excellent $\left(r^{2}>0.99\right)$.

The stevioside and rebaudioside A retention time (RT) were $5.28 \pm 0.05 \mathrm{~min}$ and $6.91 \pm 0.10 \mathrm{~min}$ (mean \pm standard deviation) respectively, with the HPLC method. Figure 3 shows the stevioside and rebaudioside A mean concentrations ( $\% \mathrm{w} \mathrm{w}^{-1}$ dry leaf) for each sample and the respective rebaudioside $\mathrm{A} /$ stevioside ratio. The rebaudioside A-concentrations were lower in all the genotypes compared to the stevioside ones. From the results, significant among sample differences existed in both steviol glycoside concentrations. Samples 10, 17, and 22 had the highest stevioside content (6.64-7.36\%), while samples 19, 20, and 29 had the highest rebaudioside A value (2.53-3.60\%). Samples 8, 11 , and 28 showed a lower concentration of both steviol glycosides compared to the other samples. Several samples revealed undetectable rebaudioside A content $(8,9,10,11$, 22, 28, and 31), considering the HPLC conditions linearity method. The rebaudioside $\mathrm{A} /$ stevioside ratio should be as high as possible, given the rebaudioside A better sweetening properties than stevioside, as previously referred. The ratio ranged from 0.17 to 0.86 , and the highest rebaudioside $\mathrm{A} /$ stevioside ratio was observed in samples 3 and 33, rating 0.81 and 0.86 , respectively (Fig. 3). Decreasing ratio values were found in samples 2, 20, and 29, with 0.60, 0.69, and 0.64 , respectively.

\section{Discussion}

The $S$. rebaudiana is undergoing domestication [31], notwithstanding that the species was used as a sweetener as earlier as the 1940s, and cultivated worldwide [ 1 and references therein]. Nevertheless, few studies reported both the 


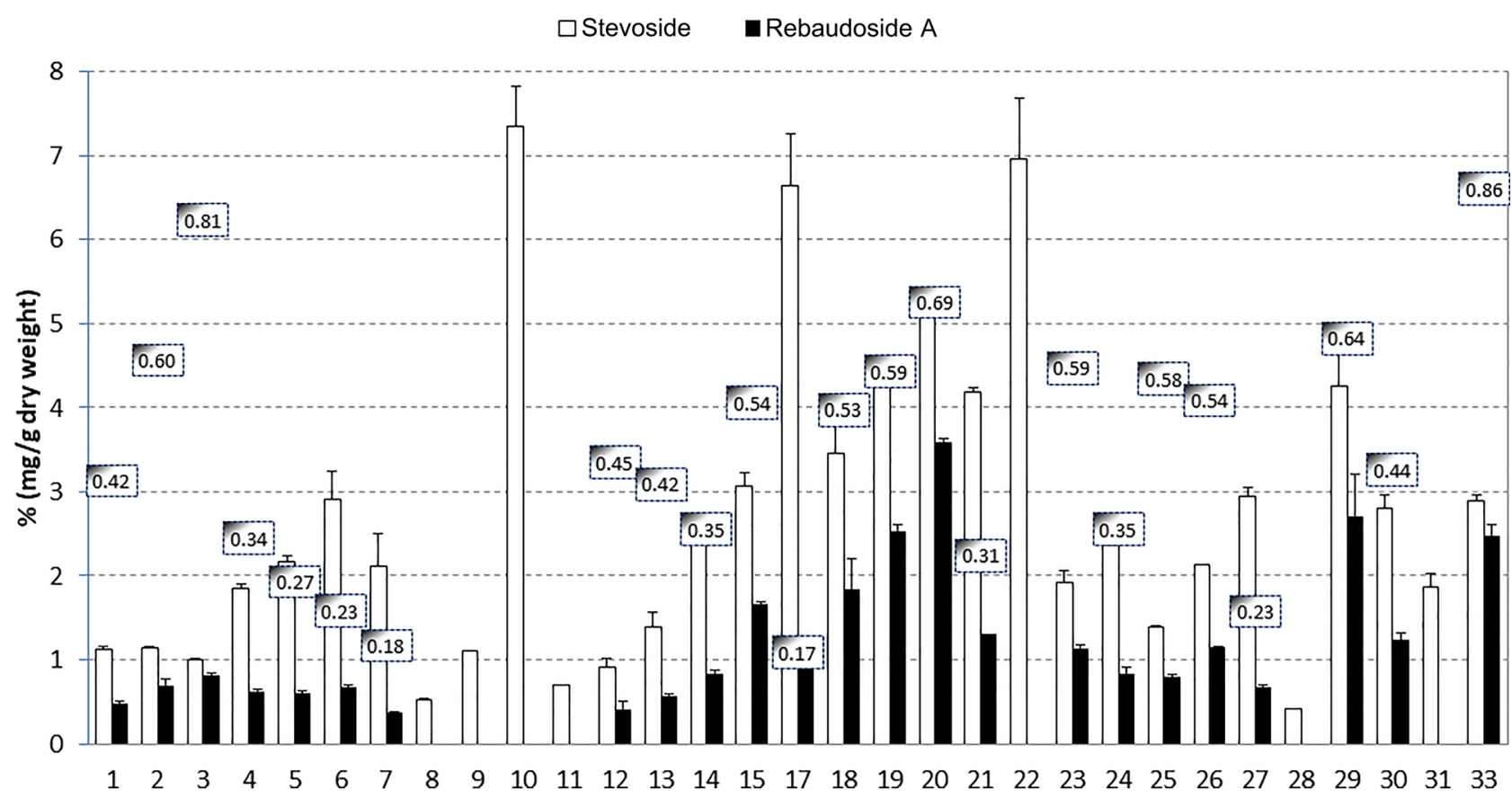

Fig. 3 Stevioside (white bars) and rebaudioside A (black bars) content (\% w w ${ }^{-1}$ dry leaf). White labels show the $S$. rebaudiana genotypes rebaudioside A/stevioside ratio. Two genotypes had the highest ratio level (3 and 33).

species genetic information and the steviol glycosides content [31 and references therein], and no study stated both the genotypes' genetic relatedness and their fingerprint. In this study, microsatellite markers were used to reveal the genetic diversity and the genetic relationship among the 31 individuals analyzed and to further detect highly similar genotypes. In the study made by Bhandawat et al. [30] the authors used 40 selected genotypes with a set of SUGMS markers and they found that the observed diversity was significantly higher than the expected one ( 0.80 and 0.63 , on average, respectively), similarly to the results from the current study (0.76 and 0.65 ). In both studies, the expected diversity was slightly lower than the observed one, resulting in a negative fixation index. But the plants used in the two studies had different origins making a genotype collection improbably in Hardy-Weinberg equilibrium. Possibly this could result in a "melting pot", meaning a mixture of individuals from different origins, and putatively with very different allelic compositions [46]. Simultaneously, the average He value (0.78) obtained by Cosson et al. [31], was higher than the value from the current study, but the authors surveyed a much larger germplasm set (145 genotypes) with a wider origin range and a high number of markers. In a meta-study surveying species with different mating systems and using nuclear microsatellite markers to evaluate genetic diversity, the observed and expected estimates were, on average, 0.65 and 0.63 , respectively [23], for the group of outcrossed species. The high level of genetic variability obtained in
S. rebaudiana is most likely due to allogamy in this species mating system [31]. Moreover, the use of an artificial population constituted by individuals from different origins could explain a high value of observed genetic diversity in our study.

Estimators are useful to identify relatives and to minimize consanguinity in breeding populations in the absence of pedigree information [44]. Different relatedness estimators exist in the literature and they respond differently to the available sample [47]. The Lynch and Ritland [43] coefficient (LR) was selected as the appropriate kinship estimator in this study, as it proved to be impartial, accurate, with a low percentage of overlapping values between kinship groups and low percentiles of exact confidence [44]. The genotypes were initially divided into two groups and distributed according to the level of similarity in the dendrogram. Considering the values of LR, two sets of individuals had the same genotype, possibly for they were the same individual due to cloning ( $\mathrm{LR}=1.0)$. Vegetative propagation was used to maintain the collection, and mislabeling is possible in these cases (Ílio Montanari Jr., personal communication). In the other cases, the LR values grouping the genotypes was very high, detecting appreciable relatedness in the group of individuals studied. Indeed, cultivar mislabelling is possible [36], and the rapid development of DNA-based molecular markers are helpful to overcome this problem.

The steviol-glycosides content and variability determination are important for the plant producers and industries to 
obtain performant cultivars through selection and breeding. Therefore, all individuals from the current study were grown in the same conditions and collected just before flowering, when steviol-glycosides content is expected to be highest. The steviol-glycosides concentrations in the current study varied between $0.53-7.36 \%\left(\mathrm{w} \mathrm{w}^{-1}\right)$ for stevioside, and $0.37-3.60 \%\left(\mathrm{w} \mathrm{w}^{-1}\right)$ for rebaudioside A. In some samples, the rebaudioside A remained undetected, probably due to either steviol-glycoside production being lower than needed for quantification by the linearity HPLC conditions or to the genotype lack of production. In general, the steviolglycosides concentrations observed in the thirty-one samples are following the values found in the literature, with stevioside content always higher than the rebaudioside A content [7, 11, 40]. Woelwer-Rieck et al. [38] reported that plants growing in a different cultivated field also showed a higher stevioside content than rebaudioside A values, with mean values of $7.90 \%\left(\mathrm{w} \mathrm{w}^{-1}\right)$ and $4.93 \%\left(\mathrm{w} \mathrm{w}^{-1}\right)$, respectively. Similar steviol-glycosides values were also obtained in another study, by water extraction, with stevioside values ranging between 3.84 and $9.36 \%\left(\mathrm{w} \mathrm{w}^{-1}\right)$, and the rebaudioside A values ranging between 2.59 and $7.77 \%\left(\mathrm{w} \mathrm{w}^{-1}\right)$ [48].

Despite the glycosides great solubility in water, some studies reported extraction with other solvents (e.g., [11]). Methanolic extracts had a range $4.10-8.20 \%\left(\mathrm{w} \mathrm{w}^{-1}\right)$ and $0.60-4.44 \%\left(\mathrm{w} \mathrm{w}^{-1}\right)$ of stevioside and rebaudioside A, respectively [39]. Analogous values have been reported in hydroethanolic extracts with a range of stevioside and rebaudioside A concentration between 3.78-9.84\% ( $\mathrm{w} \mathrm{w}^{-1}$ ) and $1.62-7.27 \%\left(\mathrm{w} \mathrm{w}^{-1}\right)$, respectively [9]. Regardless of the steviol-glycosides absolute quantity, the quality is defined by a high rebaudioside A/stevioside ratio. Indeed, the rebaudioside $\mathrm{A} /$ stevioside ratios obtained in the current study are under the numbers reported in the literature, with values ranging from 0.34 to 0.77 [9, 38]. Actually, in this study two genotypes showed interesting levels of rebaudioside A/ stevioside ratio, the genotypes 3 and 33, with 0.81 and 0.86 , respectively. In wild plants, this ratio is less than 0.5 [1]. Besides, those two genotypes were found in the two different clusters of the dendrogram, with very low LR, and they are unrelated individuals.

Comparing the genetics with the chemical results, it is worth noting that individuals 8,11 , and 28 revealed close genetic relatedness and similar chemical profile, with low steviol-glycosides concentration. Individuals 10 and 22 had displayed the same genetic fingerprint and the same chemical profile, both in stevioside concentration and absence or very low rebaudioside A synthesis. Individuals 23, 25, and 26 had the same fingerprint, and they also revealed a very similar chemical profile, being probably the same genotype/ clone. Indeed, since the late 1980s, DNA fingerprinting has become an immensely important instrument for genotype identification in wild plant and cultivated species. Additionally, when the morphological characters are mostly quantitative, correspondence with DNA marker estimates is generally quite high as compared to qualitative characters, which are more likely to reflect only a small number of mutation events [37]. But, due to this group of individuals' high relatedness, a new influx of unrelated genotypes should be included in this collection to further improve breeding and selection and avoiding relatedness. Additionally, other studies should be undertaken to reveal, e. g., genotypes' leaves biomass production and other plant characteristics that would increase steviol-glycosides production (see Ref. [1] for details).

Supplementary Information The online version contains supplementary material available at https://doi.org/10.1007/s11033-021-06308-x.

Author contributions JD, MMR and MNA designed experiments; TD and JD performed the experiments; MMR, JD and TD analyzed the data and wrote the original draft paper; MMR and MNA supervised the study; JCG and MNA were involved in funding acquisition; JD, MMR, TD, JCG, MNA and IM Jr. revised and edited the manuscript. All authors have read and agreed to the published version of the manuscript.

Funding This research was funded by the Forest Research Centre, a research unit funded by Fundação para a Ciência e a Tecnologia I.P. (FCT), Portugal (UIDB/00239/2020), and by the research unit CERNAS-IPCB also funded by FCT (UIDB/00681/2020).

Data availability All the data and material will be available upon request to the authors.

\section{Declarations}

Conflict of interest The authors have no conflicts of interest to declare that are relevant to the content of this article.

Ethical approval Sampling of Stevia samples was non-destructive. No specific permission was required to sample Stevia species in Portugal and Brazil. Field studies did not involve endangered or protected species. No humans or animals were involved in the experiments.

Open Access This article is licensed under a Creative Commons Attribution 4.0 International License, which permits use, sharing, adaptation, distribution and reproduction in any medium or format, as long as you give appropriate credit to the original author(s) and the source, provide a link to the Creative Commons licence, and indicate if changes were made. The images or other third party material in this article are included in the article's Creative Commons licence, unless indicated otherwise in a credit line to the material. If material is not included in the article's Creative Commons licence and your intended use is not permitted by statutory regulation or exceeds the permitted use, you will need to obtain permission directly from the copyright holder. To view a copy of this licence, visit http://creativecommons. org/licenses/by/4.0/. 


\section{References}

1. Yadav AK, Singh S, Dhyani D, Ahuja PS (2011) A review on the improvement of Stevia [Stevia rebaudiana (Bertoni)]. Can J Plant Sci 91(1):1-27

2. Gantait S, Das A, Banerjee J (2018) Geographical distribution, botanical description and self-incompatibility mechanism of genus Stevia. Sugar Tech 20(1):1-10. https://doi.org/10.1007/ s12355-017-0563-1

3. Soejarto DD, Compadre CM, Medon PJ, Kamath SK, Kinghorn AD (1983) Potential sweetening agents of plant origin. II. Field search for sweet-tasting Stevia species. Econ Bot 37(1):71-79. https://doi.org/10.1007/bf02859308

4. Soejarto DD, Addo EM, Kinghorn AD (2019) Highly sweet compounds of plant origin: from ethnobotanical observations to wide utilization. J Ethnopharmacol 243:112056. https://doi.org/10. 1016/j.jep.2019.112056

5. Barbet-Massin C, Giuliano S, Alletto L, Daydé J, Berger M (2016) Towards a semi-perennial culture of Stevia rebaudiana (Bertoni) Bertoni under temperate climate: effects of genotype, environment and plant age on steviol glycoside content and composition. Genet Resour Crop Evol 63(4):685-694. https://doi.org/10.1007/ s10722-015-0276-9

6. Ghanta S, Banerjee A, Poddar A, Chattopadhyay S (2007) Oxidative DNA damage preventive activity and antioxidant potential of Stevia rebaudiana (Bertoni) Bertoni, a natural sweetener. J Agric Food Chem 55(26):10962-10967. https://doi.org/10.1021/jf071 $892 \mathrm{q}$

7. Lemus-Mondaca R, Vega-Gálvez A, Zura-Bravo L, Ah-Hen K (2012) Stevia rebaudiana Bertoni, source of a high-potency natural sweetener: a comprehensive review on the biochemical, nutritional and functional aspects. Food Chem 132(3):1121-1132

8. Ceunen S, Geuns JMC (2013) Influence of photoperiodism on the spatio-temporal accumulation of steviol glycosides in Stevia rebaudiana (Bertoni). Plant Sci 198:72-82. https://doi.org/10. 1016/j.plantsci.2012.10.003

9. Munz S, Präger A, Merkt N, Claupein W, Graeff-Hönninger S (2018) Leaf area index, light interception, growth and steviol glycoside formation of Stevia rebaudiana Bertoni under field conditions in southwestern Germany. Ind Crops Prod 111:520-528. https://doi.org/10.1016/j.indcrop.2017.11.021

10. Adari BR, Alavala S, George SA, Meshram HM, Tiwari AK, Sarma AVS (2016) Synthesis of rebaudioside-A by enzymatic transglycosylation of stevioside present in the leaves of Stevia rebaudiana Bertoni. Food Chem 200:154-158. https://doi.org/10. 1016/j.foodchem.2016.01.033

11. Abou-Arab AE, Abou-Arab AA, Abu-Salem MF (2010) Physico-chemical assessment of natural sweeteners steviosides produced from Stevia rebaudiana Bertoni plant. Afr J Food Sci 4(5):269-281

12. Chen T-H, Chen S-C, Chan P, Chu Y-L, Yang H-Y, Cheng J-T (2005) Mechanism of the hypoglycemic effect of stevioside, a glycoside of Stevia rebaudiana. Planta Med 71(02):108-113. https:// doi.org/10.1055/s-2005-837775

13. Serio L (2010) La Stevia rebaudiana, une alternative au sucre. Phytothérapie 8(1):26-32. https://doi.org/10.1007/ s10298-010-0526-4

14. EU (2011) Regulation No 1131 Commission Regulation 11 November amending Annex II to Regulation (EC) No 1333/2008 of the European Parliament and of the Council with regards to steviol glycosides, pp 205-211

15. Guan $\mathrm{C}$, Zhang Y, Zhang $\mathrm{P}$, Chachar S, Wang R, Du X, Yang Y (2020) Germplasm conservation, molecular identity and morphological characterization of persimmon (Diospyros kaki Thunb.) in the NFGP of China. Sci Hortic 272:109490. https://doi.org/10. 1016/j.scienta.2020.109490

16. Yao Y, Ban M, Brandle J (1999) A genetic linkage map for Stevia rebaudiana. Genome 42(4):657-661. https://doi.org/10.1139/ g98-161

17. Chester K, Tamboli ET, Parveen R, Ahmad S (2013) Genetic and metabolic diversity in Stevia rebaudiana using RAPD and HPTLC analysis. Pharm Biol 51(6):771-777. https://doi.org/10. 3109/13880209.2013.765898

18. Dyduch-Siemińska M, Najda A, Gawroński J, Balant S, Świca K, Żaba A (2020) Stevia rebaudiana Bertoni, a source of highpotency natural sweetener-biochemical and genetic characterization. Molecules 25:767. https://doi.org/10.3390/molecules250407 67

19. Heikal AH, Badawy O, Hafez A (2008) Genetic relationships among some Stevia (Stevia rebaudiana Bertoni) accessions based on ISSR analysis. Res J Cell Mol Biol 2:1-5

20. Othman H, Osman M, Zainuddin Z (2018) Genetic variabilities of Stevia rebaudiana Bertoni cultivated in Malaysia as revealed by morphological, chemical and molecular characterisations. AJAS. https://doi.org/10.17503/agrivita.v40i2.1365

21. Luz GC, Strioto DK, Mangolin CA, Machado M (2020) ISSR markers to assess genetic diversity of cultivated populations from artificial selection of Stevia rebaudiana (Bert.) Bertoni. Breed Sci 70(4):508-514. https://doi.org/10.1270/jsbbs.20014

22. Ahmad R, Anjum MA, Balal RM (2020) From markers to genome based breeding in horticultural crops: an overview. Phyton Int J Exp Bot 89(2):183-204. https://doi.org/10.32604/phyton.2020. 08537

23. Nybom H (2004) Comparison of different nuclear DNA markers for estimating intraspecific genetic diversity in plants. Mol Ecol 13(5):1143-1155

24. Lynch M, Milligan BG (1994) Analysis of population genetic structure with RAPD markers. Mol Ecol 3:91-99

25. Hodel RGJ, Segovia-Salcedo MC, Landis JB, Crowl AA, Sun M, Liu X, Gitzendanner MA, Douglas NA, Germain-Aubrey CC, Chen S, Soltis DE, Soltis PS (2016) The report of my death was an exaggeration: a review for researchers using microsatellites in the 21st century. APPS 4(6):1600025. https://doi.org/10.3732/ apps. 1600025

26. Goldstein DB, Schlötterer C (Eds) (1998) Microsatellites. Evolution and applications, Oxford University Press, New York

27. Varshney RK, Graner A, Sorrells ME (2005) Genic microsatellite markers in plants: features and applications. Trends Biotechnol 23(1):48-55. https://doi.org/10.1016/j.tibtech.2004.11.005

28. Selkoe KA, Toonen RJ (2006) Microsatellites for ecologists: a practical guide to using and evaluating microsatellite markers. Ecol Lett 9(5):615-629. https://doi.org/10.1111/j.1461-0248. 2006.00889.x

29. Kaur R, Sharma N, Raina R (2015) Identification and functional annotation of expressed sequence tags based SSR markers of Stevia rebaudiana. Turk J Agric For 39(3):439-450. https://doi.org/ 10.3906/tar-1406-144

30. Bhandawat A, Sharma H, Nag A, Singh S, Singh Ahuja P, Sharma RK (2015) Functionally relevant novel microsatellite markers for efficient genotyping in Stevia rebaudiana Bertoni. J Genet 94(1):75-81. https://doi.org/10.1007/s12041-014-0406-8

31. Cosson P, Hastoy C, Errazzu LE, Budeguer CJ, Boutie P, Rolin D, Schurdi-Levraud V (2019) Genetic diversity and population structure of the sweet leaf herb, Stevia rebaudiana B., cultivated and landraces germplasm assessed by EST-SSRs genotyping and steviol glycosides phenotyping. BMC Plant Biol. https://doi.org/ 10.1186/s12870-019-2061-y

32. Bogado-Villalba L, Nakayama Nakashima H, Britos R, Iehisa JCM, Flores Giubi ME (2020) Genotypic characterization and steviol glycoside quantification in a population of Stevia rebaudiana 
Bertoni from Paraguay. J Crop Sci Biotechnol. https://doi.org/10. 1007/s12892-020-00066-1

33. Blouin MS (2003) DNA-based methods for pedigree reconstruction and kinship analysis in natural populations. TREE 18(10):503-511

34. Ballou JD, Lacy RC (1995) Identifying genetically important individuals for management of genetic variation in pedigreed populations. In: Ballou JD, Gilpin M, Foose TJ (eds) Population management for survival and recovery. Analytical methods and strategies in small population conservation. Columbia University Press, New York, pp 76-111

35. Govindaraj M, Vetriventhan M, Srinivasan M (2015) Importance of genetic diversity assessment in crop plants and its recent advances: an overview of its analytical perspectives. Genet Res Int 2015:431487. https://doi.org/10.1155/2015/431487

36. Scarano D, Rao R, Masi P, Corrado G (2015) SSR fingerprint reveals mislabeling in commercial processed tomato products. Food Control 51:397-401. https://doi.org/10.1016/j.foodcont. 2014.12.006

37. Nybom H, Weising K, Rotter B (2014) DNA fingerprinting in botany: past, present, future. Investig Genet 5(1): 1

38. Woelwer-Rieck U, Lankes C, Wawrzun A, Wüst M (2010) Improved HPLC method for the evaluation of the major steviol glycosides in leaves of Stevia rebaudiana. Eur Food Res Technol 231(4):581-588

39. Gardana C, Scaglianti M, Simonetti P (2010) Evaluation of steviol and its glycosides in Stevia rebaudiana leaves and commercial sweetener by ultra-high-performance liquid chromatography-mass spectrometry. J Chromatogr 1217(9):1463-1470. https://doi.org/ 10.1016/j.chroma.2009.12.036
40. Kovylyaeva G, Bakaleinik G, Strobykina IY, Gubskaya V, Sharipova R, Al'Fonsov V, Kataev V, Tolstikov A (2007) Glycosides from Stevia rebaudiana. Chem Nat Compd 43(1):81-85

41. Doyle JJ, Doyle JL (1990) Isolation of plant DNA from fresh tissue. Focus 12:13-15

42. Peakall R, Smouse PE (2012) GenAlEx 6.5: genetic analysis in excel. Population genetic software for teaching and research-an update. Bioinformatics 28(19):2537-2539. https://doi.org/10. 1093/bioinformatics/bts460

43. Lynch M, Ritland K (1999) Estimation of pairwise relatedness with molecular markers. Genetics 152(4):1753-1766

44. Ribeiro MM, Sanchez L, Ribeiro C, Cunha F, Araújo J, Borralho N, Marques C (2011) A case study of Eucalyptus globulus fingerprinting for breeding. Ann For Sci 68(4):701-714. https://doi.org/ 10.1007/s13595-011-0087-x

45. Rohlf FJ (2000) NTSYS-pc: numerical taxonomy and multivariate analysis system, version 2.1. Exeter Publishing, New York

46. Bucci G, Gonzalez-Martinez SC, Le Provost G, Plomion C, Ribeiro MM, Sebastiani F, Alia R, Vendramin GG (2007) Range-wide phylogeography and gene zones in Pinus pinaster Ait. revealed by chloroplast microsatellite markers. Mol Ecol 16(10):2137-2153. https://doi.org/10.1111/j.1365-294X.2007.03275.x

47. Milligan BG (2003) Maximum-likelihood estimation of relatedness. Genetics 163(3):1153-1167

48. Kaplan B, Turgut K (2019) Improvement of rebaudioside A diterpene glycoside content in Stevia rebaudiana Bertoni using clone selection. Turk J Agric For 43:232-240

Publisher's Note Springer Nature remains neutral with regard to jurisdictional claims in published maps and institutional affiliations. 